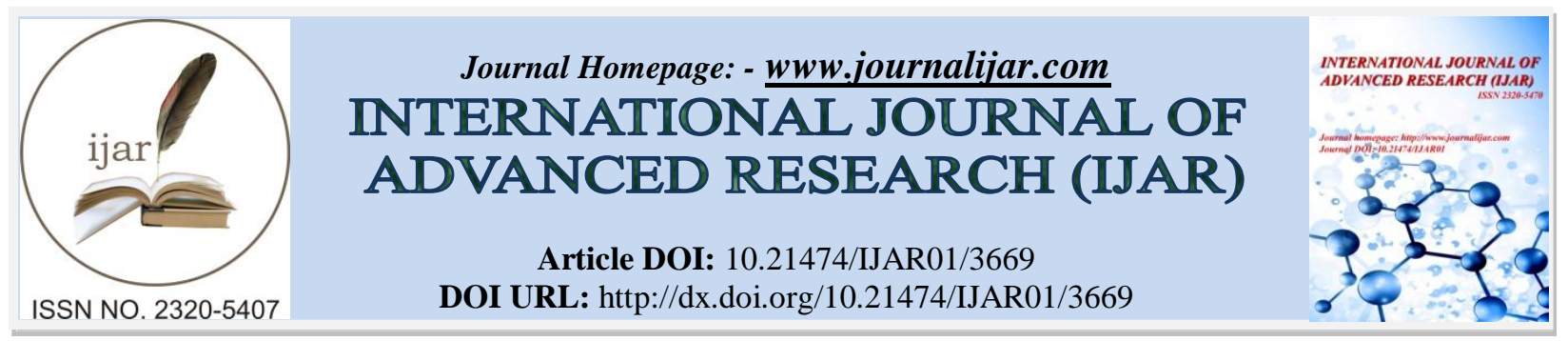

RESEARCH ARTICLE

\title{
ETHNOBOTANICAL STUDY AND CONSERVATION STATUS OF MEDICINAL PLANTS IN AND AROUND YAYO FOREST, OROMIA REGION, SOUTHWEST ETHIOPIA
}

Garuma Gerbaba Chemeda ${ }^{1}$ and Girma Mosisa ${ }^{2 *}$.

1. Department of Biology, Faculty of Natural and Computational Sciences, Mettu University, Mettu, Ethiopia.

2. Department of Biology, Collage of Natural Sciences, Jimma University, P.O.Box 378, Ethiopia.

\section{Manuscript Info}

Manuscript History

Received: 11 January 2017

Final Accepted: 06 February 2017

Published: March 2017

Key words:-

Conservation, Ethnobotany, local people, Medicinal plants, Yayo.

\section{Abstract}

The study was conducted to investigate the Ethnobotanical Study and Conservation Status of Medicinal Plants in and around Yayo forest. The purpose of the study was to document and analyze information on the use, conservation and sustainable use of medicinal plants. Data collection was accomplished through active participation of healers and familiar elders who practice traditional medicine locally. A variety of Ethnobotanical techniques were used to collect the data: semistructured interview, field observation and group discussion. Data were analyzed quantitatively and by Microsoft office excels. A total of sixty nine (69) plant specimens belonging to thirty four (34) families and sixty one (61) genera were documented and identified both in the field and the National Herbarium, Addis Ababa University. From the total documented medicinal plant species, about $42.63 \%$ are used to treat human ailments while $36 \%$ are used to treat livestock ailments and $22.27 \%$ are used to treat both livestock and humans. Among the documented families, family Fabaceae had the highest species richness followed by Asteraceae, Euphorbiaceae, Lamiaceae, Moraceae, and Poaceae. To protect and conserve this forest, appropriate management strategy and awareness creation is very crucial. As it was recommended, some cultural believes and traditional practices associated with traditional medicines were found to be contributed much for the conservation of medicinal plants in the study area.

Copy Right, IJAR, 2017,. All rights reserved.

\section{Introduction:-}

Ethnobotany is a multidisciplinary science defined as the interaction between plants and people or the study of the relationship between plants and people: From "ethno" - study of people and "botany" - study of plants (Debela Hunde, 2001). It focus on how plants have been or are used, managed and perceived in human societies and includes plants used for food, shelter, medicine, divination, cosmetics, dyeing, textiles, for building, tools, ornamentation, currency, clothing, rituals, social life and music (Choudhary et al., 2008).

Basic quantitative and experimental ethnobotany includes basic documentation, quantitative evaluation of use and management and experimental assessment. Today, ethnobotanical surveys include applied projects that have the potential to improve poverty levels of these people, allowing them to make more educated decisions about their 
future directions (Graves, 1996). These new approaches enhance the quality of the science, provide compensation for the cultural groups and take into account environmental concerns.

This modern approach is based on an interdisciplinary team usually composed of an Ethnobotanist, an anthropologist, an ecologist and a physician (Etana Tolasa, 2007). The preliminary results of a study on behalf of WHO has shown that the number of individuals using medicinal plants is large and on the increase, even among young people. It is not just in developing countries that medicinal plants are important (Endalew Amenu, 2007).

Medicinal plants and traditional medicine play an important role in the health care system of most developing countries. In Ethiopia about $80 \%$ of human population and $90 \%$ of livestock rely on traditional medicine (Choudhary et al., 2008). In light of the importance of these resources that provide the health care needs for the majority of human and livestock population in Ethiopia, and also the fact that medicinal plants could be used as sources of revenue for farmers (STCP, 2005). Efforts made to conserve forests in general and medicinal plants in particular. However, it did not have significant impact as they did not take into account the interests of the local community by failing to include farmers in decision making processes (Teklu Tesfaye and Thomas, 2004). Lack of continuity of the already initiated conservation efforts, tenure insecurity, lack of awareness and participation by local communities in different project phases, impacts of population growth and resettlement are the major factors contributing to forest degradation (STCP, 2005).

Today many medicinal plants face extinction or severe genetic loss, but detailed information is lacking. For most of the endangered medicinal plant species no/less conservation action has been taken (Erlangung and Fakultat, 2009). Therefore, this study was designed to give scientific information and methodology on how to use medicinal plants in sustainable manner and how to conserve these medicinal plants.

\section{Materials and Methods:-}

\section{Study Area:-}

The research was conducted at Yayo district particularly in and around Yayo forest, which is found in Ilu Abba Bor zone, Oromia Regional State that is found at $564 \mathrm{~km}$ Southwest of Addis Ababa, the capital City of Ethiopia and $36 \mathrm{Km}$ from the zonal capital of Mettu Town. The study area is located between $8^{0} 2^{\prime} 42^{\prime \prime}$ North and $8^{0} 31^{\prime} 18^{\prime \prime}$ North latitude and $35^{\circ} 37^{\prime} 48^{\prime \prime}$ East longitude. The district has a total area of 162,901 hectares $\left(1,629.01 \mathrm{~km}^{2}\right)$ that constitutes 9.97 percent of the total land of the zone.

Yayo is one of the few areas in the country that is endowed with a variety of vegetation types including few species found only in Ethiopia. This forest covers about 90,890.7 hectares constituting 58.8 percent of the total area of the district. Yayo forest represents the largest (10,000 ha) undisturbed forest fragment kept for the conservation of wild Coffea arabica population earlier identified as a potential Coffee gene reserve (Teklu Tesfaye and Thomas, 2004). The mean annual temperature is about $23^{\circ} \mathrm{C}$ ranging between $18.59^{\circ} \mathrm{C}$ mean minimum annual temperature and $27.88^{\circ} \mathrm{C}$ mean maximum temperature. The physical conditions and variations in altitudes have resulted in a great diversity of Climate, Soil and Vegetation which in turn, has brought about the evolution of many plant species with large diversity. The rainfall pattern of the districts varies annually from 1,191.6 to $1,960.7 \mathrm{~mm}$ showing variations from year to year. It is a unimodal type of rainfall that increases from May to October and declines in November. The district has three agro-climatic zones which includes highland (Badda); temperate (Badda-daree) and lowland (Gammoojji). Such diverse climatic conditions and habitats partly contributed to the occurrence of high species diversity in plants and animals, making Ethiopia.

\section{Study Design:-}

Materials used for the study was Plant cutter, Plant frame, Magazine, Blotter and Belt. The interview of key informants, focus group discussion, direct observation, and household survey were the main techniques used in the primary data collection. In-depth interview was conducted with experts and professionals at different levels of administrative staff, community representatives, elders, traditional healers and farmers. The plant specimens were identified in the field and by consulting experts. In addition to this it was compared with plants specimens which was already collected and identified from different parts of the country and found in the National Herbarium of Addis Ababa University, Ethiopia; and by referring the flora book of Ethiopia and Eretria. The name of family, genus and species as well as growth habit were identified and recorded. 


\section{Methods of Data Collection:-}

Quadrants Methods: Quadrants $\left(20 \mathrm{~m} \times 20 \mathrm{~m}\right.$ or $\left.400 \mathrm{~m}^{2}\right)$ in size were laid down purposefully along transects at 100 meters distance in three sites which was randomly selected in the site of study area for collecting of plant specimens. Frequency of medicinal plant individuals were counted and recorded. GPS was used to record the data of altitude, latitude and longitude of each quadrant of the study area. The collected data were recorded, summarized and entered into Microsoft offices excel for analysis. In the case of data analysis different methods for analyzing of quantitative data were used.

\section{Results:-}

\section{Medicinal Plant Resources of the Study Area:-}

A total of 69 medicinal plants were recorded in the sites of study area. Out of these collected and identified plant species, the greater numbers of Medicinal plants were from the wild vegetation. These species belong to thirty four (34) different families and sixty one (61) genera. Among these thirty four (34) families, family Fabaceae was represented by ten (10) species followed by Asteraceae, Euphorbiaceae, Lamiaceae, Moraceae, and Poaceae were represented by four (4) species for each. Family Meliaceae was represented by three (3) species while Acanthaceae, Boraginaceae, Malvaceae, Musaceae, Myrtaceae, Rutaceae, Verbenaceae and Zingiberaceae were represented by two (2) species. The remaining sixteen families had one (1) species each (Figure 1).

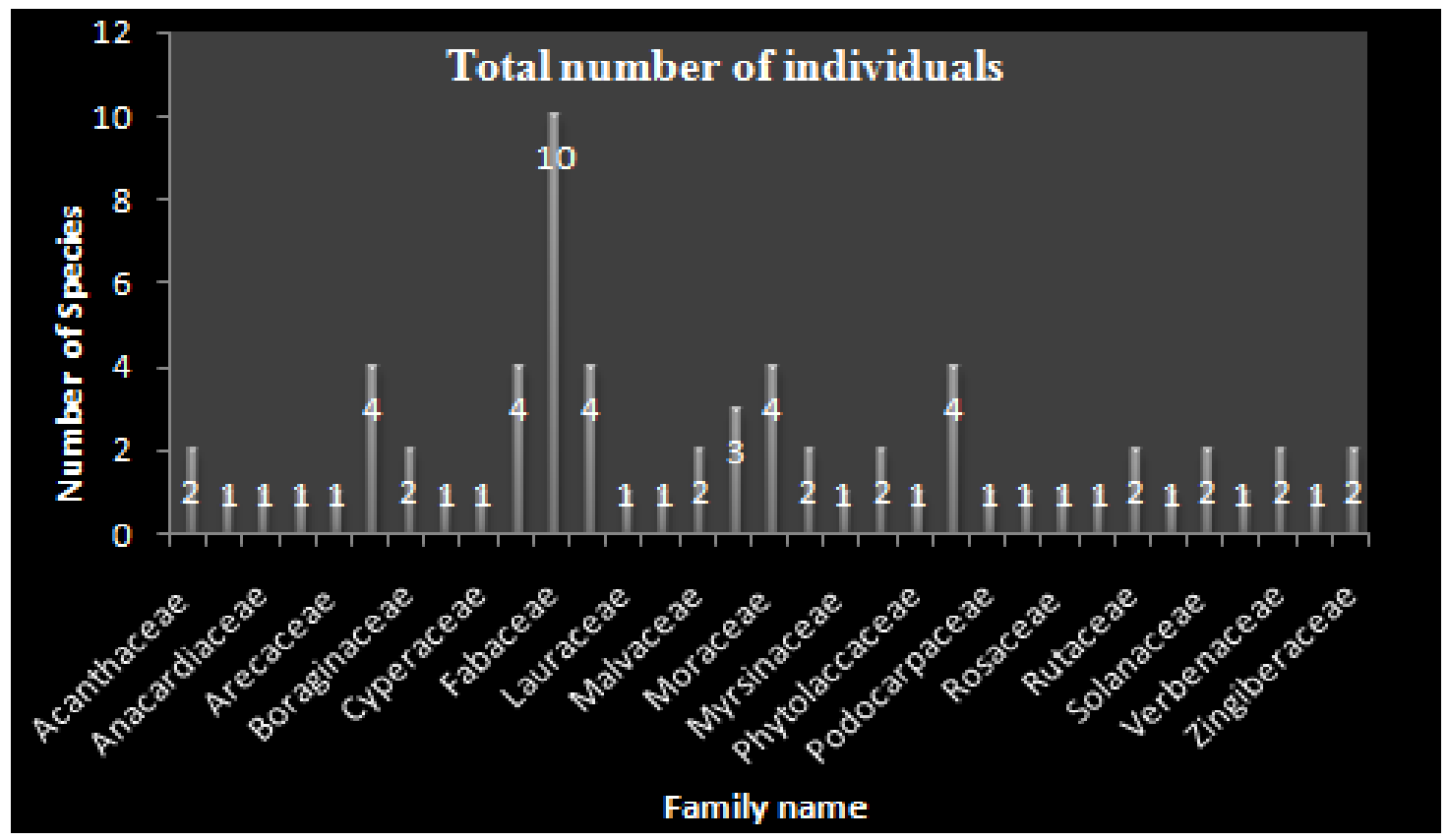

Figure 1:- The families' name with total number of individuals documented in the study area

The result point out that relatively more family Fabaceae were found at the sites of study area and they are used as medicinal values for treatment of disease for both human beings and livestock compared to the remain families. Concerning habit diversity; herbs were the most common and stood first with (23 species), followed by trees ( 22 species) and shrubs (19 species, and climbers ( 2 species) and the remaining were like epiphytes.

From the total documented medicinal plant species from the study area, about $42.63 \%$ were used to treat only human ailments while about $36 \%$ were used to treat livestock ailments and about $22.27 \%$ were used to treat both livestock and humans. The sustained existence and utilization of such a large number of medicinal plants by people in the study area indicates that the majority of the people used and continued to use indigenous medicinal practices for different ailments (Table 1). 
Table 1:- The percentage use of medicinal plants to treat various ailments found in the study area

\begin{tabular}{|l|l|}
\hline Useful Medicinal Plants to Treat Various Ailments & Total percentage \\
\hline To treat human ailments & $42.63 \%$ \\
\hline To treat livestock ailments & $36 \%$ \\
\hline To treat both humans and livestock & $22.27 \%$ \\
\hline
\end{tabular}

From 69 plant species, 29 plant species were used to treat human ailments while 25 plant species were used to treat livestock ailments and 15 plants species were used to treat both humans and livestock respectively (Figure 2).

\section{Total Number of Medicinal plants}

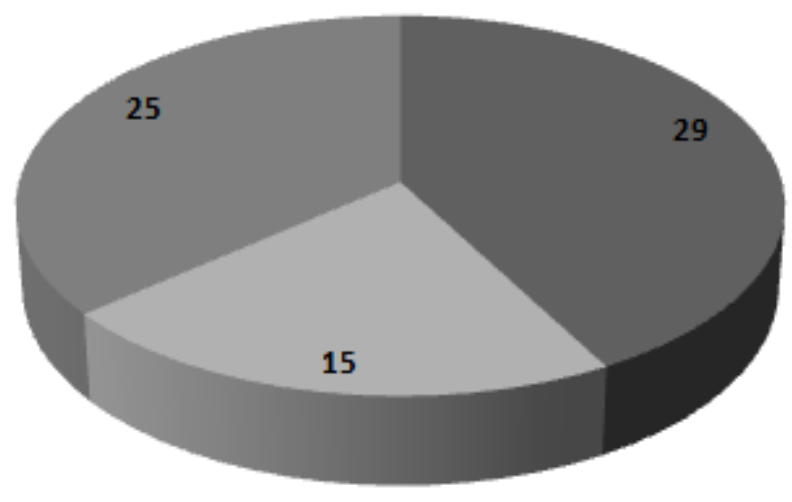

To treat human ailments

To treat livestock ailments

To treat both humans and livestock

Figure 2:- The number of useful medicinal plants used for treatment of various ailments

\section{Threats and Conservation of Medicinal Plants:-}

\section{Threats to Medicinal Plants:-}

The cause of threats to medicinal plants can be generally grouped in to natural and human induced factors. However, as reported in this study most of the causes for the threats to medicinal plants and associated knowledge were the anthropogenic factors such as deforestation due to over exploitation of plants for different uses/charcoal, fire woods, construction woods, overgrazing, cutting and burning of plants to create new agricultural lands ,medicinal plants trade for different uses and others.

The results of the present study showed that agricultural expansion, fuel woods (charcoal and fire woods), harvesting for construction and urbanization and over grazing and medicinal plants for the threats to medicinal plants and associated knowledge of the plants in the study area. The other reason for the threats of the knowledge of medicinal plant was modernization and refusal to practice/ inherit the knowledge by new generation. As reported by the informants, the expansion of modern health institutions, schools some environmental and cultural modifications reason for the losses (threats) of the knowledge of medicinal plant. 


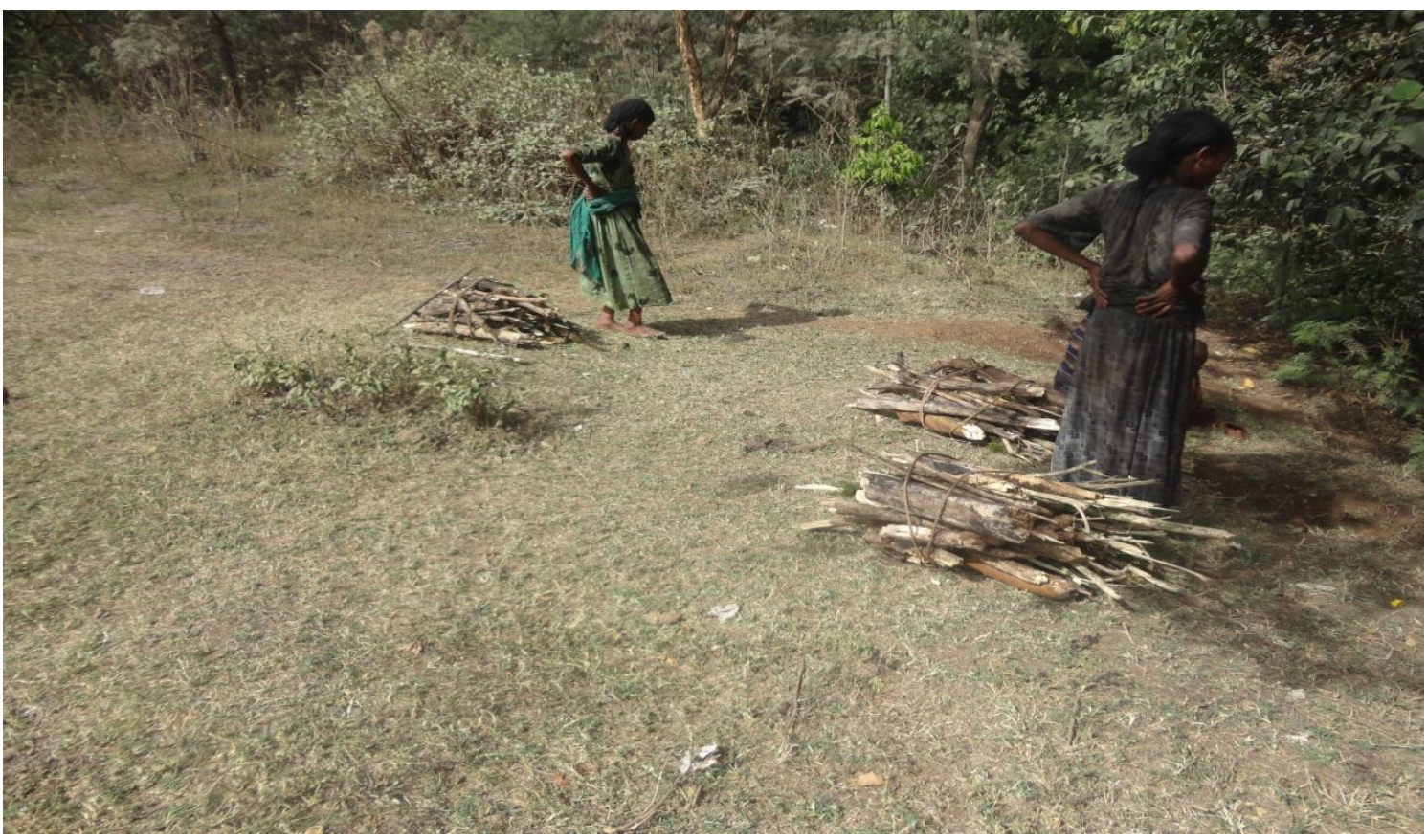

Figure3:- Collecting of plants for firewood and other purposes by local community.

\section{Discussion:-}

Medicinal principles are present in different parts of the plant like root, stem, bark, heartwood, leaf, flower, fruit or plant exudates. These medicinal principles are separated by different processes; the most common is being extraction. Extraction is the separation of the required constituents from plant materials using a solvent (Paroda, 1993).

\section{Descriptions of the most frequently reported medicinal plants used to treat different ailments Vernonia amygdalina Del. (Astraceae) Eebicha (Afaan Oromoo):-}

Is shrub or small tree usually branched from near the base and it is $2-10 \mathrm{~m}$ high. The leaves are used to wash the materials during the preparation of locale beer (Tella) and katikala (Areke) with that of Rhamnus prinoides. In Ethiopia it is found in many parts including Bale, Gamo-gofa, Gonder, Gojam, Tigray, Shewa, and Ilu Abba Bor (Edwards et al., 2000). Elsewhere in Ethiopia, the leaves and bark are bitter and used in local medicine for instance, in the study area it is used for the treatment of skin infections and sudden sickness (Dhukkuba tasaa).

\section{Solanum incanum L (Solanaceae) Hiddii (Afaan Oromoo):-}

Solanum incanum is a shrub up to $1.5 \mathrm{~m}$ high, but often less, seasonally deciduous, found in heavily grazed areas, Waste places, in altitude of above $2100 \mathrm{~m}$, Solanaceae. In Ethiopia it is found in Gonder, Sidamo, Bale, Shewa, Tigray, Gamo-gofa and Ilu Abba Bor. This form is common in Somalia and the Sudan and widespread in tropical Africa, the Middle Eastland India (Edwards et al., 2000).

Ocimum lamifolium Hochst .ex Benth. (Lamaceae) Damakesee (Afaan Oromoo):-

Is sub shrub or shrub, $0.7-3 \mathrm{~m}$ tall a very common species of primary and secondary mountain forest and Bush lands, tall grasslands, rarely also cultivated as an ornamental. In Ethiopia it is found in Gojam, Gonder, Kefa, Shewa, Ilu Abba Bor, and Wollega. In Africa it found in East Africa, Malawi, Democratic republic of Congo and Cameron (Edwards et al., 2000). In the study area this plant is used for treatment of head ache, eye infection and other related diseases.

Descriptions of the most frequently reported medicinal plant species used to treat livestock:Nicotiana tabacum L. (Solanaceae) Tamboo (Afaan Oromoo):-

An erect and it is annual or biennial herb growing to $2.5 \mathrm{~m}$ high. It is a cultivated plant in home gardens in some parts of the country and sometimes escaped into waste ground and along streams at altitudes range of between 1700 and $2400 \mathrm{~m}$, Solanaceae. In the study area, it is found in farmers' home garden or under the shade of life fence. It has a medicinal use for internal parasites, Trypanosomiasis, eye infection and headache. The local people use this plant 
to treat for human disease). Leaf of Nicotiana tabacum is pounded with root of Carissa spinarum, mixed with water and cup of tella given to patient. In addition, dried and powdered leaf of Nicotiana tabacum sniffed by human for relive to headache, and its leaves with the leaves of Capparis cartilaginea used to treat cough.

\section{Descriptions of the most frequently reported medicinal plants used to treat both human and livestock disease} Croton macrostachyus Del. (Euphorbiaceae) Bakkannisa (Afaan Oromoo):

It is shrub or tree, 2-25m long. Found in forest margins and secondary woodlands, extending in to disturbed areas and along edges of roads, mostly in soils of volcanic origin, an altitude range so far recorded for the plant is 5002350m, Euphorbiaceae. In Ethiopia, this plant is found in Tigray, Gonder, Gojam, Wello, Shewa, Arsi. Wollega, Ilu Abba Bor, Kefa, Sidamo, Bale and Harerge. In Africa it is distributed west to Guinea, south to Angola, Zambia, Malawi and Mozambique (Edwards et al., 2000). The stem bark of this species is also known for its medicinal value in treating leprosy. In the study area this plant is more effective for the treatment of ringworms, gonorrhea and rabies.

\section{Phytolacca dodecandra L.Herit. (Phytolaccaceae) Handodee (Afaan Oromoo)}

It is semi- succulent, scrambling shrub to $10 \mathrm{~m}$ tall or more. It grows in ever green bush lands, forest edges and distributed places in altitudinal range of 1500-3000m, Phytolacaceae. In Ethiopia, this plant is found distributed in Tigray, Bale, Gamo-Gofa, Gonder, Wollo, Gojam, Wellega, Shewa, Ilu Abba Bor, Kefa, Arsi, Sidamo and Hararge regions. It is also found in other African countries in Eritrea, Madagascar and in tropical and South Africa. It is widely used as soap specially for cleaning cotton cloths, also as Molluscicides for the control of the snails that are vectors of Bilharzias. The importance of this plant due to molluscidal properties has led to setting up of the Endod Foundation, with its head quarter in Addis Ababa. Endod varieties with high molluscidal content have been identified and are now being cultivated by farmers. In the study area this plant is used for treatment of malaria and rabies (Edwards et al., 2000).

\section{Conservation of Medicinal Plants:-}

Although various threats have profound effect on medicinal plants, local people attempt to grow medicinal plants in home garden though the effort is minimal. For instance, some people and/ or office have started conserving the plants by in-situ method (in original/natural habitat), fenced/protected pasture land at different worship areas (churches, mosques, etc) in their (farms' field/farm margins and so on. And also conserving by ex-situ method/ outside the original/ natural habitat/ like in and around their farmers' home gardens, live fences of the gardens, plantation fields, and so on were started in the study area. As reported by Moa Megersa (2010), home gardens are central target for in-situ and ex-situ conservation of traditional medicinal plants.

\section{Conclusions:-}

The study reported that medicinal plants have revealed that there was an insight of the local indigenous knowledge on the utilizing of medicinal plants from the study area. The study was also inferred that sixty nine (69) different plant species belonging thirty four (34) families and sixty one (61) genera were identified and recorded. Of these different families documented; family Fabaceae was found to be represented by ten (10) species followed by Asteraceae, Euphorbiaceae, Lamiaceae, Moraceae, and Poaceae were represented by four (4) species for each. Family Meliaceae was represented by three (3) species while Acanthaceae, Boraginaceae, Malvaceae, Musaceae, Myrtaceae, Rutaceae, Verbenaceae and Zingiberaceae were represented by two (2) species. The left over families had one (1) species for each.

Out of sixty nine documented medicinal plant species from the study area about $29(42.63 \%)$ of them were found to be used to treat human ailments while about 15 (36\%) were used to treat livestock ailments and about $25(22.27 \%)$ were used to treat both livestock and humans. The main use of medicinal plants are to treat human diseases than livestock ailments by local people as they pointed that; the local communities of the study area seek to find traditional medicine for their ailments first and then after for livestock ailments. Consequently, the local people possibly gained smaller understanding of medicinal plants to treat livestock ailments than knowledge of medicinal treating human ailments. Some local communities are knowledgeable about the use and conservation of medicinal plants. This is due to a given Indigenous practices somewhat contributed to the sustained use, management and conservation of medicinal plants and multiple use of indigenous trees. Traditional medicinal plants harvested mostly from wild followed by home gardens. Furthermore, the use of medicinal plants for different purposes in addition to their medicinal value such as charcoal and firewood, construction, useful materials and other anthropogenic activities. Thus, directly or indirectly leads to threat medicinal plants. Regardless of this fact, traditional healers still 
depend to a greater extent on naturally growing species, as they believe those species in the wild vegetation are more powerful in the treatment of different ailments and health problems.

The results of the study also revealed that many wild species of medicinal plants are under pressures from various human induced factors. In addition, disinterest of young generation on traditional medicine; put the continuity of traditional medicinal knowledge under question. Because of young generation shows lack of attention to make use of and to be aware of medicinal plants from elder, the knowledge of traditional medicine possibly get rid of in the near future except that appropriate documentation is made. Furthermore, creation of awareness for young generation and other concerning body about medicinal plant uses and how elders used traditional plants to be continued to treat their livestock ailments, human ailments in proper manner and to use it in sustainable manner for future generation as well.

\section{Acknowledgement}

We would like to express our sincere appreciation to Mettu University and the researcher coordinator for the financial support during this study. We are thankful to the local communities of the district, Ilu Abba Bor Forest Management enterprise institution and other organization for their providing the necessary information about Yayo forest on the study area during data collection. We are gratefully acknowledged the late Prof. Ensarmu Kalbessa for his providing moral, constructive advice and guidance when the plants specimen identification was carried out. My thanks also extend to members of National Herbarium, Addis Ababa University, for their support throughout plant identification.

\section{References:-}

1. Choudhary.K., Singh,M. and Pillai,U(2008).Ethnobotanical Survey of Rajasthan.American-Eurasian Journal of Botany, Jodhpur (Rajasthan), India; 1: 38-45.

2. Debela Hundie (2001). Use and Management of Traditional Medicinal Plants by Indigenous People of Boosat Woreda, Wolenchiti Area: An Ethnobotanical Approach. M.Sc. Thesis, Addis Ababa University effective and better utilization. SINET: Ethiop. J. Sci., 9: pp. 61-69. Addis Ababa, Ethiopia.

3. Edwards, Mesfin Tadesse, Sebsebe Demissew and Hedberg, I. (2000). Flora of Ethiopia and Eritrea. Vol. 2, (1),Magnoliaceae to Flacourtiaceae. Addis Ababa, Ethiopia and Uppsala, Sweden.

4. Endalew Amenu (2007). Use and Management of Medicinal plants by Indeginious people of Ejaja area (Chalya Wereda) West shoa, Ethiopia:An ethnobotanical approach, M.sc.Thesis.Addis Ababa.

5. Erlangung, D. G. and Fakultät, H. L (2009). Institutions, Incentives and Conflict in Coffee Forest Use and Conservation: the Case of Yayo Forest in Iluu Abba Bora Zone, Southwest Ethiopia.

6. Etana Tolasa (2007). Use and Conservation of Traditional Medicinal Plants by Indigenous People in Gimbi Woreda, Western Wellega, Addis Ababa, Ethiopia.

7. Graves, G (1996). Medicinal Plants-An illustrated guide to more than 180 herbal plants. Bracken Books,London.

8. Moa Megersa (2010). Ethnobotanical Study of Medicinal Plants in Wayu Tuka Wereda, East Wollega Zone of Oromia Region, Addis Ababa, Ethiopia.

9. Sustainable Tree Crops Program (STCP) (2005). Ethiopia: Coffee History, Production, Economy Facts.

10. Paroda, R.S (1993). Plant resources of Indian arid Zone for Industrial Uses. In Arid Land Plant Resources, Eds. Goodin J.R. and D.K. Northinfton, Texas Tech. University, Texas, pp: 261-281.

11. Teklu Tesfaye and Thomas, B. (2004). Wild Arabica Coffee Populations under Severe Threat: Farmers Perception of Existence, Access to and Conservation. Needs in the Montane Rainforests of Ethiopia, Conference on International Agricultural Research for Development Deutscher Tropentag Berlin, 5-7.October, 2004. 